\title{
Amauta(s): Antenor Orrego como maestro de vanguardia
}

\author{
Amauta(s): Antenor Orrego as a master of avant-garde \\ Amauta(s): Antenor Orrego como mestre de vanguarda
}

\section{Javier Suárez}

HARVARD UNIVERSITY, ESTADOS UNIDOS

Master of Arts, Harvard University. Entre sus principales publicaciones

se encuentran: "La gesta del humanista o los tres giros del Cid"

(InnovaG, 2016); “¡Humanidades a la calle! Sobre el Colectivo

Interdisciplinario TXT" (Revista Letral, 2015), y "La irrupción del

recuerdo. Una interpretación de El zorro de arriba y el zorro de debajo

de José María Arguedas" (en Arguedas: las dinámicas de los encuentros

culturales, 2013). Correo electrónico: jsuarez@fas.harvard.edu

Artículo de investigación

El presente ensayo fue resultado del curso "Artes en movimiento" articulado por Doris Sommer en la Universidad de Harvard durante el 2015. El artículo se convirtió luego en parte de un proyecto de libro titulado Pedagogos de Vanguardia Peruana, que busca visibilizar a las figuras pedagógicas peruanas que tuvieron una impronta en la vanguardia poética de los años 20 y 30 . Para comenzar el trabajo, se consiguió apoyo de The fens Aubrey Westengard Fund, para investigación en Perú durante el mes de julio de 2016.

Documento accesible en línea desde la siguiente dirección: http://revistas.javeriana.edu.co 


\section{Resumen}

La primera sección del ensayo ofrece un recuento histórico de las bohemias y ateneos en el Perú en tanto semilleros de vanguardia y en relación con la Bohemia de Trujillo. En la segunda parte, se analizan las ideas estéticopedagógicas de Antenor Orrego buscando descentralizar la revista Amauta a través de la búsqueda de amautas peruanos. Asimismo, se conectan los aportes educativos del trujillano con su labor intelectual. En la tercera parte, se analiza el impacto que la obra de Orrego tuvo en las vanguardias peruanas. El hallazgo de motivos comunes en los textos de Antenor Orrego, César Vallejo y Alcides Spelucín mostrará su constante colaboración.

Palabras clave: pedagogía; poética; estilo; contradicción; límite; César Vallejo

\section{Abstract}

The first section of the essay offers a historical account of the "bohemias" and athenaeums in Peru as laboratories of avant-garde movements and in relation to Trujillo's Bohemia. In the second part, the aesthetic and pedagogic ideas of Antenor Orrego are analyzed to decentralize Amauta, the magazine, by searching for other Peruvian amautas. Likewise, the aesthetic and pedagogic contributions of Orrego are connected to his intellectual work. In the third part, the impact of Orrego's work in the Peruvian avant-garde is analyzed. The discovery of common motifs in the texts of César Vallejo, Antenor Orrego and Alcides Spelucín show their constant collaboration.

Keywords: pedagogy; poetics; style; contradiction; limits; César Vallejo

\section{Resumo}

A primeira seção do ensaio oferece um reconto histórico das boemias e ateneus em Peru em tanto berçários de vanguarda e em relação com a boemia de Trujillo. Na segunda parte, analisam-se as ideias estéticopedagógicas de Antenor Orrego visando descentralizar a revista Amauta através da procura de amautas peruanos. Mesmo assim, conectam-se as contribuições educativas do trujilhano com sua lavor intelectual. Na terceira parte, analisa-se o impacto que a obra de Orrego teve nas vanguardas peruanas. $\mathrm{O}$ achado de motivos comuns nos textos de Antenor Orrego, César Vallejo e Alcides Spelucín mostrará sua constante colaboração.

Palavras-chave: pedagogia; poética; estilo; contradição; limite; César Vallejo

\section{Cómo citar este artículo:}

Suárez, Javier. "Amauta(s): Antenor Orrego como maestro de vanguardia". Cuadernos de Literatura 22.43 (2018): 120-145. https://doi.org/10.11144/Javeriana.cl22-43.aaom 
"El espíritu es en cada hombre un estilo. Ama tu estilo".

ANTENOR ORREGO

\begin{abstract}
"Quiero abrazar este libro, constructivo y calentador como ningún otro lo ha sido en tan amorosa significación para mí; quiero abrazarlo, y adorarlo, y emborracharme de él, hasta enraizarlo plenamente en mi corazón y en mi vida, hasta que cada una de sus páginas se me prenda a los costados, a mis propias hojas en blanco".

CÉSAR VALLEJO SOBRE NOTAS MARGINALES
\end{abstract}

A Ricardo González Vigil

Al Grupo NOR

\title{
Introducción: Amauta(s)
}

En 1926, José Carlos Mariátegui expresaba su deseo de publicar una revista llamada Vanguardia y su interés por crear un ateneo. ${ }^{1}$ La revista saldría unos meses más tarde con el nombre quechua Amauta. ${ }^{2}$ En una entrevista al diario Mundial de Lima, un mes después (el 23 de julio de 1926), Mariátegui caracteriza a su generación del siguiente modo: "Yo no puedo concebirla sino como una generación eminentemente constructiva. Y muy realista y muy idealista al mismo tiempo. Nada de fórmulas utópicas, nada de abstracciones brumosas" (Mariátegui 158). Esta descripción me aleja hoy de la capital peruana y me lleva al Norte. Pero no vaya a creer el lector que me refiero a la patria de Whitman. No. Estoy en Trujillo, al norte de Lima. Y allí me encuentro con Antenor Orrego (Cajamarca 1982-Lima 1960), filósofo y amauta, amigo y pedagogo, quien detonó la vanguardia peruana norteña a través de una fascinante pedagogía estética.

1 "Vuelvo a un querido proyecto detenido por mi enfermedad: la publicación de una revista crítica, Vanguardia. Revista de los escritores y artistas de vanguardia del Perú y de HispanoAmérica. Me intereso por la creación de un ateneo de Estudios Sociales, Económicos y Educacionales. Y reviso y perfecciono el plan de un libro sobre el Perú que me propongo escribir muy pronto" en Variedades (Lima, 6 de junio de 1926); transcrito en Fénix 10 (Lima, 1954); en José Carlos Mariátegui (Obras Completas 145-146).

2 Durante el periodo inca, los amautas (del quechua: hamawt'a; 'maestro', 'sabio') se dedicaban a la educación formal de los hijos de los nobles y del Inca (Larroyo 113-116). 
La obra de Antenor Orrego, al igual que la de Mariátegui, me revela dos rasgos de la vanguardia en el Perú: su carácter pedagógico y su hibridez. Prefiero este último término al de mestizaje, ya que no pretende una síntesis perfecta, sino que da cuenta del encuentro en constante transformación de diversos agentes culturales. De la relación entre vanguardia estética y pedagógica la crítica peruana ha escrito poco; asimismo, pedagogos y filósofos, precursores y/o acompañantes de los vanguardistas peruanos, no han sido suficientemente comprendidos como parte de esta generación.

El presente ensayo se dividirá en tres partes. La primera sección ofrecerá un breve recuento histórico de las bohemias y ateneos en el Perú en tanto semilleros de vanguardia y en relación con la Bohemia de Trujillo (luego Grupo Norte). En la segunda parte, se analizarán las ideas estéticopedagógicas de Orrego, buscando descentralizar a Amauta a través de la búsqueda de amautas peruanos y, asimismo, se conectarán los aportes estético-pedagógicos del trujillano con su labor intelectual (e institucionalista) ${ }^{3}$ de promoción y gestión de grupos culturales.

En la tercera parte, se analizará el impacto constructivo que la obra de Orrego tuvo en las vanguardias peruanas. Recuérdese el reconocimiento que uno de los artistas más originales de la vanguardia peruana, César Vallejo (algo similar puede decirse del poco recordado Alcides Spelucín, miembro de la Bohemia), hace del educador trujillano. El hallazgo de motivos comunes en los textos de Orrego, Vallejo y Spelucín mostrará su constante colaboración horizontal, productiva y, sobre todo, nacional.

\section{De la Bohemia de Trujillo al Grupo Norte: espacios de vanguardia pedagógica}

Cuando se piensa en la vanguardia, el arte aparece como protagonista. Sin embargo, no suele repararse en los procesos educativos ${ }^{4}$ que los vanguardistas atravesaron y que dejaron huella en su quehacer estético. En este sentido, es la figura del maestro de vanguardia la que se presenta como agente pedagógico-estético de estos procesos. Es en este contexto que Antenor Orrego se revela como maestro y con-discípulo de un grupo de vanguardia peruana cuyo eje no fue Lima, sino Trujillo en la costa norte.

3 Para una descripción y análisis de la labor de Orrego como creador y gestor de instituciones educativas, véase Robles. Este ensayo se centrará en sus ideas estético-pedagógicas.

4 Que puede tomar diversas formas: educación formal (primaria, secundaria o superior), educación alternativa, educación entre pares (grupos, clubes, revistas, bohemias, ateneos). 
Este amauta excéntrico promovió, a través de una intensa acción cultural, el fortalecimiento y enriquecimiento de un grupo que renovó la política y el arte peruanos: la Bohemia de Trujillo.

Las bohemias, a caballo entre los siglos XIX y XX, fueron agrupaciones espontáneas ${ }^{5}$ y contestatarias (Mosquera 247), antecedentes de ese espíritu provocador que tendrán las vanguardias. Piénsese, por ejemplo, en la bohemia romántica cuyo más famoso representante fue Ricardo Palma (1833-1919) quien será parte, en una etapa posterior, del Ateneo de Lima.

En el caso peruano, continuidades y rupturas entre bohemias y ateneos revelan la tensión entre el espíritu contestatario y constructivo que los caracterizó. Este fenómeno se observa, por ejemplo, en la relación entre el Club Literario de Lima y el Círculo Literario. Aquel se funda en 1872 con el fin de elaborar una historia nacional. Su estrategia consistía en recuperar y conservar los documentos históricos y literarios del pasado para conformar la identidad del país. El escritor poseía un papel fundamental en la configuración de lo nacional y buscaba diseñar sobre los textos del pasado un discurso sugerente para los lectores que lograse difundir la historia. ${ }^{6}$

Sin embargo, luego de la guerra con Chile, en octubre de 1886, se funda el Círculo Literario formado por jóvenes bohemios (opuestos a Ricardo Palma, figura hegemónica del statu quo literario), quienes manifiestan su molestia con el academicismo del Club Literario. La figura más importante del Círculo fue Manuel Gonzáles Prada (1844-1918), amauta de la vanguardia peruana, quien estaba en contra de los académicos y a favor de los vulgarizadores: la escritura tenía como deber educar al pueblo. Los miembros del Círculo buscaban la creación de modelos que desplazaran a los europeos y una genuina literatura nacional. En 1899, Palma publica $L a$

5 Como afirma Peralta, "fueron los lazos familiares y las relaciones de amistad provenientes de la infancia, del seminario de San Carlos y San Marcelo y de la universidad" (47) los que mantuvieron unidas las actividades del grupo.

6 En agosto de 1885, luego de la guerra con Chile, se reinician las actividades del Club Literario de Lima. La literatura tuvo entonces la misión de explicar los motivos de la derrota del país en el conflicto con Chile y proponer las reformas para el progreso nacional (desarrollo de la industria, agricultura, minería y comercio; se busca la inmigración europea). En noviembre de 1885, el Club Literario de Lima cambia su nombre a Ateneo de Lima. Para los ateneístas, los escritores no podían ser indiferentes al destino de la nación, pues con sus trabajos colaboraban con la construcción de la nacionalidad; por lo tanto, la escritura se convirtió en un deber, a través de ella se podría edificar "lo bueno" y demoler "lo malo" (aquello que causó la derrota en la guerra) para crear el carácter nacional. 
bohemia de mi tiempo que incluye un retrato sobre su juventud romántica entre 1848 y 1860 aproximadamente.

A pesar de sus oposiciones, bohemias y ateneos en Lima coincidieron en la necesidad de construir una identidad nacional a través de un discurso sugerente o de vulgarizadores con el fin de promover un sentido común nacional y, consecuentemente, una hegemonía cultural y política. En el caso trujillano, la transformación del nombre de la agrupación revela esta tensión. En un primer momento, el poeta Juan Parra del Riego denominó al grupo la Bohemia de Trujillo; ya para 1923, se le conocía como Grupo Norte debido a la creación del diario El Norte por Orrego (González Vigil 117-119).

Germán Peralta distingue lúcidamente entre los bohemios europeoparisinos y los peruano-trujillanos: aquellos se encuentran "en una zona crepuscular entre la ingeniosidad y la criminalidad. Son excéntricos, visionarios, rebeldes a toda disciplina y arrojados de sus familias; por lo tanto, pobres temporal o permanentemente" (45). Según el crítico, basándose en la caracterización que de la bohemia de París hace Jerrold Seigel (15), el grupo trujillano no calza en este paradigma europeo, ya que los trujillanos no llegaron a "asimilar y consagrarse totalmente a un tipo de vida marginal, ni menos aún a una ruptura con el sistema" (46).

Los miembros de la Bohemia de Trujillo, en cambio, "irrumpieron en el ambiente trujillano con un discurso de cambio y modernización, sin llegar a asumir las posturas y exageraciones parisinas" (47), pues su fin era pedagógico en el sentido de que experimentaron la necesidad de promover un renovado sentido común entre la población; en términos gramscianos, la Bohemia de Trujillo buscó crear hegemonía a partir de una intensa campaña pedagógica en todos los frentes posibles: estético, político, ideológico, periodístico (creación del diario El Norte que rebautiza al grupo), etc. Esta preocupación político-pedagógica distingue a las vanguardias latinoamericanas de sus pares europeas y su afán de ruptura.

Este juicio debe matizarse, ya que las tendencias político-pedagógicas (en tanto creación de hegemonía nacional y/o continental) varían de vanguardia en vanguardia europea, de allí que considere que deben releerse las vanguardias europeas y latinoamericanas: no es lo mismo la ruptura internacionalista del dadaísmo que el afán nacionalista y altamente políticopedagógico del futurismo italiano. 


\section{Límite, contradicción, estilo y armonía: \\ la pedagogía estética de Antenor Orrego}

Antenor Orrego fue lector del filósofo francés Henri Bergson; su encuentro con Bergson estuvo mediado por el trabajo del filósofo y educador peruano Pedro Zulen (1889-1925), titulado La filosofía de lo inexpresable: bosquejo de una interpretación y una crítica de la filosofía de Bergson (920). Los inicios del siglo XX en el Perú se caracterizan por una crítica al positivismo en diversos ámbitos. Luego del desastre de la Guerra del Pacífico, la sociedad peruana buscaba nuevas formas de encarar el futuro y es el cambio de siglo el que verá el nacimiento de originales propuestas en diversos campos de la cultura.

El llamado espiritualismo (o vitalismo) de Bergson fue introducido, en tanto crítica al positivismo, por el filósofo Alejandro Deustua. Pedro Zulen y Mariano Iberico, ${ }^{7}$ estudiantes de aquel, fueron quienes leyeron y adaptaron a su modo la filosofía de Bergson. La figura de Zulen es clave, ya que fue uno de los primeros divulgadores no solo de la filosofía vitalista sino también del pragmatismo en el Perú, siendo crítico de la primera, aunque reconociendo su valor, y expresando sus simpatías por la segunda. Zulen tuvo un contacto directo con el pragmatismo norteamericano debido a su breve estancia en la Universidad de Harvard, la cual tuvo que dejar debido a problemas de salud que finalmente lo llevarían a una prematura muerte.

En el Prólogo a La nave dorada de Alcides Spelucín (poeta perteneciente a la Bohemia de Trujillo que aglutinó a diversos intelectuales, entre ellos César Vallejo y Víctor Raúl Haya de la Torre, y que se convertirá en el Grupo Norte), Antenor Orrego describió del siguiente modo la experiencia educativa del grupo:

Aprendimos que era preciso vivir conforme a nuestros pensamientos sin traicionar jamás a nuestra intimidad; todos éramos catecúmenos y maestros y, a la vez que aprendíamos de los otros, dábamos también sin reservas de lo nuestro. Creo, y me he convencido de ello, que ésta es la única docencia viva. (23)

La experiencia educativa de Orrego puede resumirse en la idea de $d o$ cencia viva; esta revela dos tradiciones que permean el pensamiento peruano de inicios de siglo XX: el espiritualismo que hace de la categoría "vida" la central de su filosofía en tanto que ella no es aprehensible sino a través de

Filósofo peruano (1892-1974). 
la intuición que capta la vida como experiencia y no bajo los parámetros de la ciencia positiva. Junto a la experiencia, es la docencia en tanto compartir de conocimientos entre pares la que les da sentido "noble y superior" a los miembros de la Bohemia, quienes pudieron "adueñarse de" y "reeducarse con" aquello que la educación oficial no les ofrecía.

Orrego critica sin ambages las carencias de la educación formal y afirma que la comunidad educativa de amigos es capaz de superar estas deficiencias, "así se explica que sin cultura previa y sin maestros pudiéramos vivir al día con el pensamiento contemporáneo más avanzado" (Orrego, "Palabras Prologales" 23). Cuando afirma que se encontraban "sin maestros", el gesto crítico oculta un revés de esperanza: frente a la falta de una educación formal son los mismos jóvenes quienes se convierten en "catecúmenos y maestros a la vez".

El uso de la palabra catecúmeno revela el carácter religioso que para Orrego tenía la Bohemia. Un catecúmeno es una persona que se instruye en la doctrina y los misterios de la fe católica con el fin de recibir el bautismo. En este sentido, cada uno de los miembros de la Bohemia trujillana se instruía recíprocamente en un modo renovador de ver la realidad peruana. Nuevamente, se ve cómo el espiritualismo (religioso) convive con el pragmatismo.

En una crónica poco conocida de marzo de 1918 (recuérdese que el primer poemario de Vallejo, Los heraldos negros, se publica en julio de 1919 aunque con fecha de 1918), el poeta describe a Orrego como el pensador del grupo, como una especie singular de intelectual que buscaba "vivir la poesía"; nuevamente la categoría vida sale a la luz. Vallejo le pregunta a Orrego: “¿Y por qué no escribe, Antenor? ¿Por qué no publica?"; a lo que el amauta trujillano responde:

Antes que nada -me dijo con gran optimismo- hay que vivir la poesía de nuestra vida personal, cómo es, cómo se desliza, en desnudo, en plenitud de sangre, sin forzarla, sin mistificarla con nada artificial, ajeno o pegado, sin siquiera patinarla de colores que no le nazcan de adentro, que no le sean naturales. Y después de saber crear esta suprema obra de arte que se llama vida, el espíritu dará lo demás, cuando llenas nuestras propias copas el vino se desborde y se regale en espuma, rubíes y borbotear sinfónico. (Vallejo, "La intelectualidad" 202)

A este vitalismo debe agregársele la necesidad de renovar y transformar el país al cual encuentra en una crisis profunda. En otras palabras, el vitalismo se mezcla con un optimismo estético y ético que a través del 
arte busca la transformación personal (la vida de cada ser humano es una estética) y, al mismo tiempo, nacional (buscar personalmente una estéticaética nacional y latinoamericana). Esta relación entre vitalismo estético y pragmatismo pedagógico responde a un contexto histórico: ¿qué hacer después de la Guerra con Chile? ¿Cómo reconstruir el país luego de la debacle política y cultural cuya punta de lanza era el positivismo europeo, primero de un Comte e, inmediatamente después de la Guerra, del de un Spencer pesimista?

Pablo Quintanilla (2009) ha sugerido la relación entre la Guerra de Secesión Norteamericana y el surgimiento del Pragmatismo (sobre todo en la versión de Peirce y Dewey) como respuesta al desastre que supuso la guerra civil para la política y la cultura norteamericana. Una hipótesis similar, que no desarrollaré en este ensayo, pero vale la pena mencionar, es que la aparición de una pedagogía estética de vanguardia en las dos primeras décadas del siglo XX responde a los retos que un contexto postbélico impone a un estado-nación. Sin duda, valdría la pena preguntarse por el desarrollo vanguardista chileno (vencedor en la Guerra del Pacífico) que desarrolló un programa estético más cosmopolita y menos nacionalista alineado con las vanguardias europeas. El caso peruano, y su hibridez nacional, fue distinto.

En este sentido, la propuesta híbrida de Orrego puede denominarse como una pedagogía estética basada en cuatro motivos (en el sentido musical) vitales: el límite, la contradicción, el estilo y la armonía. La vida, para el trujillano, es una obra de arte, el estilo único de cada persona. No es casualidad que, en Notas marginales, texto de 1922 y que antecede a Trilce por meses, luego de la introducción y una nota ideológica (suerte de propedéutica para el texto), Orrego coloque a la estética como el "más alto valor humano para llegar al corazón del universo, a la suma de todas las concreciones y de todo conocimiento, es decir, al conocimiento, es decir, a Dios" ("Notas marginales" 27).

De esta convicción se desprende uno de los rasgos más productivos de la obra de Orrego (asimismo presente en Vallejo): la metáfora como materialización histórica de una estética personal, ya que cada ser humano elabora y reelabora un estilo a lo largo de su vida; de allí que la vida se vuelve una obra de estilo: "El espíritu es en cada hombre un estilo. Ama tu estilo" (113), afirma Orrego en El monólogo eterno de 1929. Piénsese en el poema "Retablo" de Los heraldos negros (118) que es un homenaje por la muerte de Rubén Darío: 
Yo digo para mí: por fin escapo al ruido;

nadie me ve que voy a la nave sagrada.

Altas sombras acuden,

y Darío que pasa con su lira enlutada.

$[\ldots]$

Dios mío, eres piadoso, porque diste esta nave,

donde hacen estos brujos azules sus oficios.

Darío de las Américas celestes! Tal ellos se parecen

a ti! $Y$ de tus trenzas fabrican sus cilicios.

Como ánimas que buscan entierros de oro absurdo,

aquellos arciprestes vagos del corazón,

se internan, y aparecen... y, hablándonos de lejos,

nos lloran el suicidio monótono de Dios!

Darío, convertido en un Dios lírico, es cantado (idolatrado) por "arciprestes vagos del corazón", poetas-sacerdotes que imitan a Darío sin un estilo personal. Para estos poetas, incluso el suicidio se vuelve un evento lastimero y monótono. Lo más sugerente del poema es que estos poetas, al imitar el estilo que, como dijera Orrego es personalísimo y hace del hombre "una parcela de Dios" ("Notas Marginales" 52), hacen cilicios de las trenzas de Darío: instrumentos que en lugar de ser consecuencia de su expresión personal son el resultado de su pereza, de su imitación que los encadena a ser unos falsos o degradados Daríos.

Para Orrego, la estética como pedagogía, o viceversa, es vital para el desarrollo personal, para la armonía existencial del ser humano; basten las siguientes citas para confirmarlo, todas en Notas marginales, aforísticas de 1922. En primer lugar, Orrego coloca al rasgo estético, en tanto "necesidad de realizar la belleza", como anterior en importancia a la razón, al afecto y la ética:

Abstrayéndonos hacia un campo exclusivamente antropocéntrico, vemos que el hombre antes que un ser pensante, y antes que un ser ético o afectivo, es un ser estético, lo que vale decir, un ser que aspira a su máxima expresión individual. Cuando parece que es incapaz ya de amar, cuando ha sufrido la total relajación de su sentido moral, no le queda sino un hilillo que lo relaciona con el milagro del universo: su necesidad de realizar la belleza. (4)

Además de concebir lo estético como suprema categoría antropológica, el amauta trujillano afirma que frente a la total adversidad existencial (piénsese en Vallejo), es una necesidad estética la que milagrosamente permanece en 
el hombre y lo salva: la realización de lo bello. Esta necesidad tiene un valor moral y religioso que eleva al hombre y "lo acerca a Dios; le hace recordar constantemente su origen divino. Lo último que muere en el hombre es siempre el artista, el ser expresivo" (4).

Expresiones como esta recuerdan a la educación estética del hombre propuesta por Friedrich Schiller. La mención que Orrego hace del alemán en el artículo "La egolatría alemana" publicado en La Reforma en 1915, permite afirmar que el trujillano conocía y admiraba la filosofía de aquel. En el artículo, el amauta critica duramente el "brutal egoísmo del ideal teutón militarista" que había llevado a Europa a una guerra mundial; asimismo, distingue nítidamente entre la filosofía del "desenfrenado ególatra" Nietzsche y la excelsa y eficaz tradición romántica alemana:

la Alemania imperial ha olvidado el alto ideal humano de Goethe, esa ansia infinita de vivir la vida con plenitud, ese integralismo cordial que era amor y que era pasión. Los manes de Schiller, de Kant y de Hegel han de tener un gesto de dolorosa recriminación para la barbarie de esta Alemania que ha traicionado la excelsitud de su pensamiento y la eficacia de sus enseñanzas. (Peralta 292)

Asimismo, no es posible circunscribir la vida-arte del hombre a un conjunto de leyes; las únicas normas permisibles son aquellas que nacen de la necesidad expresiva de la persona singular; de allí que para Orrego la ley no sea nunca definitiva sino la definición de un conjunto de posibilidades siempre abiertas al cambio:

Cada hombre ejerce su don estético según su manera personal de concebir la vida, según su posición singular y circunstancial ante el universo. Por eso, nada más absurdo que establecer cánones, pragmáticas o leyes para realizarlo. Toda preceptiva ha sido, es y será siempre el eterno enemigo de nuestro don estético, el cual no acepta más limitaciones que las del propio espíritu que tácita, espontánea e inconscientemente las encuadra dentro de sus posibilidades y potencias que se dictan sus reglas a sí mismas. La ley, pues, nunca tiene un valor absoluto; no es más que la definición de una posibilidad o de un conjunto de posibilidades. $(4)^{8}$

8 Compárese el pasaje orreguiano con el ensayo de Hart Crane titulado "Modern Poetry" de 1930: "No work of true genius", he says, "dares want it's appropriate from, neither indeed is there any danger of this. As it must not, so genius cannot, be lawless: for it is even this that constitutes its genius: the power of acting creatively under laws of its own origination" (170). 
Junto con el estilo, la contradicción y el límite dan forma a la pedagogía estética orreguiana. La contradicción es necesaria cuando el estilo personal contradice la fría lógica (positivismo); la coherencia vital para Orrego se encuentra en no contradecirse según la dinámica ley del propio estilo que no es sino metáfora de la vida individual y social: "Me contradigo ante las lógicas, pero no ante mi lógica que explica mi unidad. ¿Qué culpa tengo yo de que la concordancia racional y sentimental que se da en mí, se produzca como contradicción o dislocación en el cerebro, y en el corazón de los otros?" ("Notas marginales" 54$).{ }^{9}$

La aceptación de la contradicción es semejante a la de Walt Whitman, quien afirma celebratoriamente "Do I contradict myself? Very well, then I contradict myself, (I am large, I contain multitudes)". Orrego, sin embargo, se desvía creativamente de Whitman, como lo hace de Emerson, ya que para el trujillano la contradicción es algo más que la consecuencia de la multiplicidad infinita que es un ser humano; sin negar esto, Orrego pone el énfasis en el reconocimiento de la contradicción humana como condición para asumir nuestra trágica transitoriedad en el proceso histórico de buscar la armonía vital.

Estos pasajes revelan los intercambios y las hibridaciones entre vitalismo y pragmatismo. En otras palabras, Orrego evita cualquier posición extrema: ni un espiritualismo tan radical que olvide las transformaciones históricas a causa de un ideal ajeno a cualquier cambio ni un pragmatismo que reduzca todo a los dictados de la materia; como se verá, Pedro Zulen y Antenor Orrego, filósofos y educadores peruanos, muestran muy sugerentes correspondencias que sin duda tendrán una impronta en César Vallejo y Alcides Spelucín. Orrego se introduce en una tradición moderna que hace de Nietzsche y Emerson dos figuras fundacionales; sin embargo, no se queda tranquilo con imitar el molde estadounidense o europeo, él lo comenta, lo adapta, lo transforma y lo corrige: "El hombre, desde que nace, tiende a expresarse, a definirse, a explicarse ante los demás. Acciones, palabras, voli-

9 Véanse estos dos pasajes de Notas marginales (aforísticas): "Siento que consumaría el más grande crimen contra mí mismo si renunciara a priori, antes de verificar mi experiencia, a intentar mi posibilidad personal, a mi rol de creador. Me contradigo con respecto a las razones de los demás porque soy un organismo vivo; porque la vida no puede reducirse a un silogismo, so pena de amputarla y hacerla mezquina" (54) o "el sectario, el prosélito, el académico, el fanático, el profesional; el hombre de una idea, de una fe, de una disciplina o de una acción, elimina de su vida el elemento más fecundo, el elemento heroico, el elemento de libertad por excelencia: la contradicción; elimina la tragedia, constriñendo y deformando su vida hasta hacerla perfectamente lógica" (56). 
ciones, sentimientos se dirigen a cumplir este fin, a satisfacer esta necesidad vital. 'La mitad del hombre, ha dicho Emerson, es su expresión'. Yo creo que la expresión es todo el ser humano" ("Notas marginales" 29).

Este vitalismo-pragmatismo estético exige transformar la sociedad. En el prólogo a La nave de oro, Orrego valora la convivencia entre amigos, entre "catecúmenos y maestros", pero reconoce que esa sola actividad no basta, ya que sería caer en un esteticismo o diletantismo. De allí que con respecto a esa primera parte afirme que "era la faz interna, disciplinaria y doméstica" del grupo, pues este tenía, además, "una faz expansiva, contagiante, objetiva sobre el público. No queríamos resignarnos a hacer vida de 'torre de marfil' y de cenáculo. Nos parecía mezquina, egoísta y estéril. Era preciso salir de nosotros mismos, y salimos" ("Palabras Prologales" 19). Este pasaje muestra la otra cara de la moneda en la pedagogía vanguardista del trujillano: hay una necesidad "objetiva", hay un "público" y a él se debe llegar saliendo de sí mismo: encuentro, diálogo, intencionalidad. Orrego, a continuación, describe la necesidad de "chocar con todo":

Como no éramos, no podíamos ser conformistas, porque hubiera sido la negación de nosotros mismos, tuvimos que chocar con todo y con todos. Las instituciones, los poderes públicos, las convenciones sociales, la universidad, la plutocracia explotadora e insolente, las mentiras consagradas, las rutinas de clase, la falta de honestidad y de honradez, el servilismo rebajado, la expoliación del trabajador, el burocratismo, la política profesional, la ignorancia presuntuosa, etc., etc., hubieron de sufrir en carne viva nuestros ataques. (19)

La Bohemia de Trujillo (Grupo Norte) no tuvo un manifiesto programático al estilo de las vanguardias europeas; la retórica del grupo no era bélica sino pedagógica y estética. La figura del catecúmeno-maestro se hace visible en los géneros que usaron los miembros del grupo para expresar sus ideas: el diario (periodismo), los prólogos y el arte. Los documentos que describen apasionadamente al grupo son el prólogo de Orrego y el poco conocido artículo de Vallejo. En otras palabras, se debe tener en cuenta que la vanguardia trujillana no nace como una vanguardia de ataque, con el conocido tono militar, sino como colectivo de amautas que deseaban, imbuidos de amor -"Nadie podrá hacer con más amor este prólogo que yo, y también nadie con más imparcialidad, aunque suene a paradoja" (22)-, cambiar su sociedad, lo que Orrego llama "docencia combativa" (19). ${ }^{10}$

10 Sin duda, esta afirmación recuerda lo que Paulo Freire llamará pedagogía de la autonomía desde América Latina. 
Otro motivo de la pedagogía estética orreguiana es el concepto de límite como causa del sufrimiento y, al mismo tiempo o debido a él, la necesidad de transformación. Para Orrego, el ser humano está siempre con sed de infinito, sin embargo, la ley de la vida material es la imposibilidad de alcanzarlo, he allí la causa del dolor, de la tragedia. Es esta imposibilidad la que permite al hombre moverse y transformarse buscando la mejor expresión de su vida, ya que la "realidad concreta es una simple metáfora" (Orrego, "Palabras Prologales" 28). Se podría buscar los antecedentes de esta visión en filósofos europeos, y sin duda los hay; no obstante, esta idea de limitación y transformación es expresada por Pedro Zulen, filósofo idealista-pragmatista, híbrido, a través de las categorías de resistencia y transformación; en "Sentido del límite" (El monólogo eterno), Orrego afirma:

Ama tu propio límite, porque si no tu límite te devora. Sé tan humilde hasta estar orgulloso de tu pequeñez. No hay sino una manera de vivir y de expresar las cosas: amar tu limitación. No hay sino una manera de no vivir y de no llegar nunca a la expresión: eludir tu limitación. [...] Sin embargo, escucha: no vayas a amar tanto tu límite que tus ojos queden ciegos para siempre. [...] Sólo hay una clase de individuos que ven demasiado y que no miran nada; que jamás pueden amar su propio límite: los idiotas carecen de humildad y están incapacitados para el orgullo.

Amar el infinito, querer beberlo en un sólo sorbo y no poder darse éste a nosotros sino gota a gota, limitándose cada día, prostituyéndose en una técnica: ¡he aquí la opresora tragedia de la vida! (86-87)

Pero esta limitación, esta tragedia, no le impide decir a Orrego que "hombre soy y en mí se realizan estupendas posibilidades" ("El monólogo eterno" 51). Para Zulen, a través de quien Orrego leyó a Bergson, la limitación es causa del más grande dolor de la vida, pero, a su vez, lleva a la transformación (debido al intento de aprehender lo inaprehensible, lo absoluto, Dios, como en Orrego). Para Quintanilla, el pensamiento de Zulen evidencia un realismo sui generis, ya que "no se trata de un realismo metafísico según el cual el mundo está ( $\mathrm{sic}$ ) articulado es en sí mismo independiente de la manera en que lo concebimos, ni de un idealismo psicológico que afirma la posibilidad de conocer el mundo partiendo del conocimiento de nuestra propia conciencia" $(153) \cdot{ }^{11}$

11 El realismo sui generis de Zulen se sostiene sobre dos principios. En primer lugar, sobre el principio de que hay un mundo independiente de objetos externos que ofrecen una 
Para Orrego, es la metáfora el modo cómo se lucha por este ideal concreto en la vida: las ideas se viven, las metáforas se expresan a partir de una realidad concreta. Asimismo, esta valoración de la limitación, de la carencia como potencialidad será fundamental en la obra de Vallejo y Spelucín y su original visión de Cristo, como revolucionario material del dolor y/o la esperanza.

En esta sección, se ha caracterizado a Antenor Orrego como maestro de la vanguardia trujillano-peruana a través de varios motivos: la docencia combativa y horizontal, la contradicción, el chocar con mesura, la estética como el más alto valor humano, el ser humano como estilo en constante transformación, el límite como causa del dolor (tragedia existencial) pero como necesario para su transformación (optimismo vital). Estos rasgos también se observan en la poesía de Spelucín y Vallejo; en la siguiente sección, abordo las continuidades y rupturas de los motivos orreguianos en la obra de ambos poetas; pero sobre todo, se hará énfasis no en el Vallejo poeta del dolor, como la crítica lo ha caracterizado por más de medio siglo, sino en el Vallejo poeta de la esperanza que nace del dolor o, en términos de Orrego, el poeta de la vida que nace de la limitación de la misma o, en términos de Jacoby (2011), el poeta cuyo deseo nace del derrumbe.

\section{Tríada revolucionaria: Orrego, Vallejo y Spelucín}

Dos de los textos más proteicos y poco estudiados de la vanguardia peruana son un poemario, La nave dorada (1926) de Alcides Spelucín (1895-1976), y su prólogo, escrito por Antenor Orrego. El libro ha sido catalogado como modernista; sin embargo, puede ser leído junto a Los heraldos negros (1918) de César Vallejo, formando una pareja revolucionaria (de vanguardia). Hacer dialogar a estos dos textos y encontrar sus afinidades y rupturas fue la sugerente hipótesis estética que Orrego propuso en el prólogo al libro de Spelucín.

Uno de los motivos claves de la pedagogía estética orreguiana, y que aparece en este prólogo, es comprender la realidad misma como metáfora: "En el pensamiento vulgar sin hondura metafísica y trascendente, la forma se desplaza de su ejercicio funcional, de su fin cósmico, hasta hacerse negativa y ciega. Es el materialismo estético de cierto arte que no comprende que la realidad concreta es una simple metáfora" ("Palabras Prologales" 24). Orrego, a

resistencia, de modo que "si yo violo sus leyes, una pared puede aplastarme, una locomotora dividirme, acabando con mi vida" (Filosofía de lo inexpresable). El segundo principio señala que el mundo externo no está para ser conocido de manera ingenua, sino para ser transformado (154-155). 
continuación, critica al parnasianismo como aquella corriente que destacó lo decorativo como valor estético supremo.

Luego, hace lo propio con el positivismo literario "que no acepta más instrumento de conocimiento que la experiencia" (24); para Orrego, debido a esta corriente, "nunca se estrechó y se rebajó hasta tal grado el espíritu del hombre [...] que desechó tanta luz y tantas revelaciones vitales" (24). La estética orreguiana no elimina etapas de una necesaria progresión histórica que ve el pasado como primitivo y superado. Por el contrario, encarna una visión holística de la aparición de las formas personales de expresión cuya existencia tiene como fin lo que él denomina constantemente la "armonía vital en el espíritu del hombre"; de allí que para que esta armonía sea posible, el parnasianismo-positivismo y su otro extremo, el racionalismo idealista, hayan sido "históricamente necesario(s)" para la realización de esta armonía vital que el prologuista encuentra en Vallejo y Spelucín.

En la tercera sección del prólogo titulada "Categorización estética", Orrego define las poéticas de los poetas en torno a las categorías de virginización $^{12}$ y revolución; de modo sugerente, visionario y provocador Orrego ve en sus jóvenes (con)discípulos dos formas de la revolución:

En César Vallejo, la categoría estética es la virginización técnica del verbo para que se adaptara a la virginidad de su visión. En Alcides Spelucín, la realidad estética categórica es la virginización formal de las cosas, o mejor, la virginización funcional de la forma que está siempre petrificada y yerta para el ojo vulgar. Por eso, mientras el uno es un revolucionario de la retórica, el otro es un revolucionario del significado vital de la forma, como presencia real y objetiva. Y es curioso constatar, que mientras el revolucionario de la forma estética deja intactas las formas de la realidad objetiva; el revolucionario de la representación funcional de las formas objetivas deja intactas las formas tradicionales de la estética.

He aquí dos puertas por donde es posible vislumbrar, tal vez, el destino remoto, pero inexorable y fatal, de una América, hermética todavía, pero que ha comenzado a organizar su verbo para el grito de la revelación". ("Palabras Prologales" 24-25)

12 Esta categoría es análoga a la de familiarización que propone Shklovsky como característica del arte moderno: interrumpir los hábitos para experimentar la realidad de nuevo. 
El americanismo de Orrego $^{13}$ se ve al final del pasaje en el cual se presenta a los poetas como posibilidades de la revolución americana que se interpreta y siente como destino. La visión histórica de Orrego, que también se desprende de este pasaje, podría denominarse evolución orgánico-estética, ${ }^{14}$ es decir, la historia de la liberación del hombre se le "revela" como inexorable destino pero no en el sentido de un eliminativismo positivista o una dialéctica hegeliano-idealista sino como una progresión guiada por una armonía vital que tiene como fin la encarnación de la expresión (estilo, metáfora) del hombre que anhela su perfección y la de quienes lo rodean. ${ }^{15}$

Existen, para el destino americano, dos modos de llegar a esta armonía vital, a esta historia como experiencia estética, a saber, la poética de Vallejo y la de Spelucín. La caracterización orreguiana está teñida de un lenguaje cristiano-evangélico; para él, ambas poéticas revelan una virginización, es

13 En 1939, Orrego escribe Pueblo-continente. Ensayos para una interpretación de América Lati$n a(117-278)$.

14 A propósito de este motivo, véase el ensayo de Charles S. Peirce (1839-1914) "Evolutionary Love" aparecido en The Monist (176-200).

15 Nótese la mención que Orrego hace de Jacob von Uexküll (1864-1944), biólogo estonio-alemán, romántico, quien comprende la realidad como un sistema musical y propone una teoría musical de la naturaleza; Orrego afirma en sus "Palabras Liminares" de El monólogo eterno (1929) lo siguiente: "Van estas frases liminares al frente de un libro que ha ido articulándose sin premeditación ni plan alguno. Su armonía es interna y sin duda alguna, es una armonía en el sentido de que nos habla Von Uexküll" (109). Para el biólogo "el origen de todo ser viviente semeja punto por punto una melodía; solo que en vez de ser sonidos, son células las que resultan ordenadas rítmicamente" (Cartas biológicas 77); y en otra parte afirma que "la melodía funcional no es una regla que pueda derivarse de la estructura $[\ldots]$ es un factor que vela sobre el curso ordenado de las funciones, haciendo que, según las necesidades, un órgano reemplace a otro, regulando el crecimiento según las exigencias de la función, ordenando constantemente el mecanismo del cuerpo. Es, en suma, una regla dominante y no una regla derivativa" (83). Orrego transforma esta biología musical en una estética musical del hombre que actúa en la historia en busca de su más perfecta melodía, de su armonía vital; en Notas marginales afirma que en la música "se reconstituye la Naturaleza en su máxima síntesis armoniosa, en su total unidad, en su integridad perdurable. Vierte el mundo, tan esencial y primariamente, que llega a herir y traducir todas las conciencias, constituyendo, de este modo, el único lenguaje universal" (30); y en otra parte, conduce todo tipo de arte a la expresión musical: "el artista no es propiamente tal, no es propia mente grande sino hasta que ha encontrado su expresión estética suprema: la música de su arte" (31), de allí que concluya que "el grado máximo de subjetivación estética es el universo traducido en notas, reducido a música" (43). Otra fuente de esta concepción musical del mundo orreguiana es el concepto medieval-renacentista, de cuño platónico, de las esferas celestes como fuentes de música celestial. Lo interesante es que Orrego mencione a un biólogo y no a un filósofo o místico, dando así materialidad a su concepto de vida. 
decir, un nuevo modo de experimentar la realidad. Nótese la sutil diferenciación que se establece entre ambas poéticas. En el caso de Vallejo, se ha producido una nueva técnica verbal que se adapta a la nueva visión de la realidad del poeta, el verbo "se virginiza" debido a la novedad existencial del autor. En el caso de Spelucín, en cambio, la novedad se produce al nivel de las formas de las cosas, o de la función de esas formas, que la cotidianidad no cuestiona y esclerotiza.

A partir de esa caracterización, Orrego afirma que Vallejo es un revolucionario de la retórica ${ }^{16}$ y Spelucín un revolucionario del significado vital de la forma como presencia real y objetiva. ¿A qué se refiere Orrego con esta "curiosa" distinción? ¿Es posible ver en este fragmento una sutil crítica a la poética de Vallejo, quien en el mismo año publica su libro más experimental? ¿ Hacer de Vallejo un revolucionario de la retórica es criticar amistosamente el experimentalismo vallejiano ${ }^{17}{ }_{\mathrm{C}} \mathrm{O}$ es, en cambio, un modo de reafirmar una manera de revolucionar la forma que obedece a un nuevo modo de experimentar el mundo?

Orrego continúa afirmando que el revolucionario de la forma estética no toca las formas de la realidad objetiva ( ${ }_{\mathrm{C} V a l l e j o ?}$ ) y que, en cambio, el revolucionario de la funcionalidad de las formas objetivas no toca las formas tradicionales de la estética (¿ínpelucín?). ¿Qué quiere decir esto exactamente? Al parecer, para Orrego, revolucionar la retórica ${ }^{18}$ (aunque esta revolución

16 Es curioso, sin embargo, que en su prólogo a Trilce (1926), Orrego diga que Vallejo se desprende de toda retórica: "El poeta quisiera vencer la trágica limitación del hombre para verter a Dios. El poeta quisiera librarse del yugo de las técnicas para expresar el crudo temblor de la Naturaleza. Más aún, "el poeta quisiera matar el estilo para traducir la desnuda y fluida presencia del ser. El poeta quisiera conocer sin estilo. [...] Es así como César Vallejo, por una genial y, tal vez, hasta ahora, inconsciente intuición, de lo que son en esencia las técnicas y los estilos, despoja su expresión poética de todo asomo de retórica, por lo menos, de lo que hasta aquí se ha entendido por retórica, para llegar a la sencillez prístina, a la pueril y edénica simplicidad del verbo" ("Palabras Prologales" 9-10); ¿ está Orrego utilizando dos sentidos opuestos del mismo término o acaso hay un cambio en la interpretación de la poética vallejiana? Recuérdese que el prólogo a La Nave Dorada se publica en 1926: la radical experimentación de Trilce ya se había producido.

17 De hecho, en el poema que Spelucín dedica a Vallejo, "Voz", se le advierte a un soñador acerca de los peligros que puede enfrentar: "iSoñador, ten cuidado! Tras esa esquina acesta / la mirada incisiva del pecado mortal" ("El trópico y el mar" 177).

18 El uso de la palabra retórica por parte de Orrego es dinámico. De allí que deba entenderse su sentido en el Prólogo: retórica es aquí estilística (uso y experimentación estética del lenguaje). En ese sentido, Vallejo es un revolucionario del estilo. 
provenga de una novedosa experiencia individual) no es capaz (quizás no lo pretende) de transformar las formas de la realidad objetiva (sociales, políticas, económicas). Por otro lado, el revolucionario de las funciones de las formas objetivas de la realidad (en otras palabras, quien critica y busca transformar la función de formas sociales) no es capaz (quizás tampoco lo pretende) de transformar o transgredir las formas estéticas, quizás de allí la tradicional categorización de Spelucín como modernista.

Del Prólogo se desprende que no hace falta elegir o eliminar una de las dos "puertas por donde es posible vislumbrar, tal vez, el destino remoto" (25) de América. Para Orrego, Vallejo y Spelucín representan dos melodías distintas y complementarias, una dualidad musical cuyos ritmos, "hermético(s) todavía" representan el futuro "grito de revelación" del continente americano. El dualismo complementario de estas dos poéticas opera para Orrego en dos frentes: la experimentación retórica individualísima de la experiencia vallejiana y el cuestionamiento de las formas sociales objetivas de Spelucín; en este sentido, la armonía musical-vital de Orrego se manifiesta estéticamente en la posibilidad de concebir dos revoluciones-motivos entrelazados, individualy-social (personal) cuyas fuerzas eventualmente serán las desencadenantes de la revolución americanista que Orrego, el catecúmeno-amauta anhela.

A continuación, se verá cómo esta diferencia poética entre Vallejo y Spelucín, vislumbrada por Orrego, puede verse en sus textos poéticos que abordan el motivo orreguiano del hombre como "parcela de Dios". Que Dios es el hombre, que el hombre es Dios, que el hombre tiene a Dios dentro de sí o que el mundo está lleno de Dios, son ideas que Orrego comparte con (¿y transmite a?) Vallejo ${ }^{19}$ y Spelucín; para Spelucín "es el Cristo sonriente de los huertos del alma"; mientras que, para Vallejo, "son las caídas hondas de los Cristos del alma".

Si para Orrego el hombre es una "parcela de Dios"; para Spelucín, esta parcela sonríe de esperanza por un dios-hombre encarnado; para Vallejo, esta parcela sufre y, sin embargo, es desde el sufrimiento que el ser humano alcanza la esperanza en la solidaridad de un dios que es hombre en la tierra. Con respecto a Vallejo, se ha dicho que su visón de la divinidad propone una religión del hombre (y no de Dios) o un evangelio del hombre (y no del superhombre). Considero que esta idea debe comprenderse asimismo en relación con las múltiples influencias que recibió de sus catecúmenos-maestros trujillanos. Los

19 Piénsese en los versos: "Dios mío, si tú hubieras sido hombre, / hoy supieras ser Dios; / pero tú, que estuviste siempre bien, / no sientes nada de tu creación. Y el hombre sí te sufre: el Dios es él!". 
motivos orreguianos en ambos poetas se aprecian mejor al analizar y comparar "El Cristo de la sonrisa" de Spelucín y "Los Heraldos Negros" de Vallejo.

El poema de Spelucín aparece en la última sección de La nave dorada, "Otros Poemas". Esta sección está compuesta por seis poemas: "Voz", "El Cristo de la sonrisa", "Las ventanas en la noche", "La canción vigorosa", "Triptolemus" y "La gran danza en La mayor". Nótese que los poemas están dedicados a conocidas figuras con una labor fundamental en la renovación educativa, poética, política, ideológica y plástica del Perú y de América. ${ }^{20}$

Los poemas de esta sección tienen un tono de lucha y celebración, es decir, dan cuenta del intenso agon vital que representa en la vida de los hombres aquella "armonía" de la que habla incansablemente Orrego; pero, además de describir los ardores de esta lucha, el yo poético celebra siempre la victoria del hombre que anhela encarnar y difundir esta armonía estético-vital, individual y social; de allí el tono celebratorio de estos poemas; ya sus títulos revelan ese tono festivo-educativo, tono triptolémico (neologismo rubendariano ${ }^{21}$ usado por Vallejo para describir elogiosamente el libro Notas Marginales de Orrego $)^{22}$ en el sentido del que enseña, maestro-amauta, las artes para vivir (agricultura) en conjunción con los misterios eleusinos (poesía).

El primer poema está dedicado a César Vallejo (renovación poética); el segundo, "El Cristo de la sonrisa" a José Vasconcelos (renovación educativa); el tercero, a José Carlos Mariátegui (renovación ideológica); el cuarto, a Víctor Raúl Haya de la Torre (renovación política), el quinto a Jose de Azpilicueta (no he podido rastrear a esta figura); y el sexto, a Esquerriloff, pseudónimo de Julio A. Esquerre Mendoza, artista del dibujo y la caricatura, trujillano también.

21 En "Salutación del optimista" de Darío, se lee: "Juntas las testas ancianas ceñidas de líricos lauros / y las cabezas jóvenes que la alta Minerva decora, / así los manes heroicos de los primitivos abuelos / de los egregios padres que abrieron el surco prístino, / sientan los soplos agrarios de primaverales retornos / y el amor de espigas que inició la labor triptolémica". Según Jorge Eduardo Arellano, triptolémico es un neologismo que Rubén deriva de Triptólemo, personaje heroico y glorioso de la mitología griega. Deméter quería hacer inmortal a Triptólemo, pero como no pudo, lo quiso compensar haciendo que todos lo amaran y le guardaran agradecimiento. Para eso, le enseñó a cultivar el trigo y a hacer el pan y luego le dio una carroza maravillosa halada por dos dragones, para que fuera a recorrer el mundo y enseñara a la gente el arte de la agricultura. Después de cumplir su misión bienhechora, Triptólemo regresó a Eleusis, construyó allí un templo a Deméter y a su hija Proserpina y fundó el culto religioso que fue llamado los Misterios Eleusinos.

http://www.laprensa.com.ni/2014/o1/24/opinion/179552-el-trigo-de-triptolemo

22 Dice Vallejo sobre el libro de Orrego: "Pienso que tendrá que operar en mi espíritu, sesgo crudo, filuda influencia. Pienso que en el Perú "Notas Marginales" tendrá igual resonancia cordial. Nunca, en verdad, supe de troncha más edificante y nutricia y pura, que este silabario de empresas y de siembra. El libro, ante todo, es para América; es libro apostólico, 
Comparar el poema de Spelucín con el de Vallejo revela rasgos interesantes de estos dos modos de revolución que Orrego veía en sus con-discípulos. Además de las sorprendentes correspondencias de ritmo y versificación, e incluso de metáforas, es el tema divino el que une y distancia, ¿complementándolos?, ¿repotenciándolos como quizás hubiese soñado Orrego?, a ambos poetas: se trata de Dios padre y de Cristo. La primera estrofa de cada uno de los dos poemas da cuenta de esta diferencia: mientras que el Cristo de Spelucín es dulce y sonriente, el Dios de Vallejo es traído a la realidad concreta a través de sus golpes y su odio que abruman la vida del hombre.

A nivel retórico, el Cristo de Spelucín utiliza el género de la parábola, narración que, a través de una comparación o semejanza, ofrece una enseñanza moral, un mensaje de optimismo. En cambio, en Vallejo, el registro retórico del yo poético es el del escéptico frente al origen y la experiencia del dolor: nada se sabe, nada se puede hacer, solo clamar en el desierto. Mientras que el poema de Spelucín es una descripción de ese Cristo que se espera, que esperamos; el poema de Vallejo no es sino la queja existencial de un hombre frente a un Dios que no comprende su sufrimiento y que nunca llega o que llega siempre tarde (cuando el dolor ya se ha hecho soberano del mundo y su historia).

Una lectura no orreguiana podría afirmar que estos textos se oponen en su caracterización de la figura divina; sin embargo, el prólogo permite comprender estos textos como dos momentos revolucionarios, como dos virginizaciones. El poema de Vallejo, piénsese en la centralidad del poema al llevar el título del poemario, ofrece una experiencia existencial, individual(ista), de un sujeto atrapado en su dolor y su queja; ese estar atrapado sin salida lo acerca a una visión decadente del mal de siglo romántico o el spleen de un poeta como Baudelaire.

$\mathrm{Y}$, sin embargo, hay dos experiencias por las que el yo poético vallejiano atraviesa, cuya conexión da forma retórica a la virginización de la experiencia: el dolor y (el atisbo) de la esperanza. El yo poético presiente la esperanza en la experiencia del dolor infinito (es esta la esperanza vallejiana en la que la crítica, al etiquetarlo como poeta del dolor, no ha reparado lo suficiente). El Destino ( $\dot{\mathrm{d}}$ la incertidumbre del yo y/o la injusticia en el mundo?) es para la voz poética una fuerza más poderosa que la propia fe, de allí que el Destino

triptolémico, sacerdotal...! Y nuestro continente, en botón, clara y yema, todavía, necesita eso: la luz de un sol obrero, en toda su diafanidad, capaz de tostar parásitos y de blindar desnudeces" (Mi encuentro 76). 
la blasfeme; la esperanza está allí, en ese pan en la puerta del horno; pero sucede algo que hace que esa esperanza se frustre, se queme.

Vale la pena detenerse brevemente en la imagen del horno, ya que para el yo poético hay un exceso de calor o de intensidad que hace que este pan, alimento evangélico, espiritual y material, del hombre, no llegue a buen término. ¿De qué fuerza o calor excesivo se trata? Podría tratarse de la fuerza infinita del dolor, metamorfoseada en ese calor excesivo que hace que el pan se queme. Y, a pesar de todo, esta experiencia de insatisfacción permite una experiencia del todo inesperada en el yo que lo hace sentir brevemente la esperanza (como el "casi" del pan quemado): "Vuelve los ojos, como cuando por sobre el hombro nos llama una palmada"; pero nuevamente, la esperanza de aquella fe adorable es vencida por la incertidumbre del yo no sé y sus intensísimos golpes.

Esta experiencia del dolor-esperanza, la virginización de la experiencia de la que hablaba Orrego a propósito de Vallejo, lleva al poeta a una experimentación retórica nunca antes vista. Sin embargo, este movimiento interioridad-retórica deja intactas, según Orrego, las formas sociales. Y es en ese preciso sentido que la poética de Spelucín complementa a la de Vallejo; el Cristo de la sonrisa complementa socialmente, parabólicamente, a los golpes de Dios y al pan que se quema en la puerta del horno; y se le espera con fe y alegría. Así, este Cristo, encarnado y revolucionario, representa la virginización de las funciones de las formas objetivas.

Como el Dios de Vallejo, el Cristo de Spelucín está en el mundo y es descrito en término físicos y, sin embargo, es un "Cristo interior al que las almas de seculares penas plasmaron la mirada inmortal del amor"; se ve cómo este Cristo complementa lo que Vallejo vislumbra en "Los Heraldos": el dolor acumulado en la historia ya no produce escepticismo sino inmortal amor frente al infinito dolor del Dios vallejiano. El movimiento de Spelucín es el del con-discípulo que sigue, a pesar de todas las dificultades históricas, al maestro-amauta-pedagogo (de allí la dedicatoria a Vasconcelos): "Él va con lento paso por las vías riscosas de los fieros instintos / Sus dos manos radiosas nos muestran el camino que lleva hacia la cumbre".

La direccionalidad de Spelucín no es la del yo que experimenta el dolor y atisba la esperanza (fallida); es la del maestro-discípulo que no duda en seguir al ideal histórico representado por un Cristo que sonríe y que se caracteriza por su capacidad de reconciliar opuestos ("Hacia la cumbre excelsa de las claras verdades, donde el podre y la rosa hallan su extraño nexo") y por su humildad y falta de cualquier pompa ("Y este Cristo sereno que desprecia 
retablos y que pasa nimbado de humildad y de calma sin gárrulas cohortes, sin Pedros y sin Pablos, es el Cristo sonriente de los huertos del alma").

La quinta estrofa del poema se revela como la más orreguiana/vallejiana en el uso de imágenes y en la versificación, ya se vio el verso clave más arriba. Agréguese a estos versos el de "sin Pedros y sin Pablos" donde se produce el uso de un sustantivo propio en plural para dar cuenta de la cotidianidad humilde de este Cristo; piénsese en el extraño/de-familiar uso de sustantivos en Los Heraldos: "Está ahora tan suave, tan ala, tan salida, tan amor" ("Los pasos lejanos") o "Y con qué esfuerzo / hacia todos los flancos / sus pies innumerables algarabía" ("La araña"). El poema culmina con una invitación a la revolución de las formas sociales objetivas que este Cristo le ofrece al hombre: “ $¡ E x a l t a d$ sus doctrinas! ¡Bebed su vino fresco!”.

En esta sección, se ha visto cómo el prólogo de Orrego ofrece claves para re-comprender su pedagogía estética y, a su vez, las poéticas de Vallejo y Spelucín como contrapunteo y complementariedad. Las voces de Orrego y Spelucín permiten así comprender a Vallejo en su contexto nacional peruano y, sobre todo, regional trujillano ofreciendo un panorama más complejo de la labor de amauta que desarrollaron Orrego y sus con-discípulos en la denominada Bohemia de Trujillo, bautizada por él como Grupo Norte.

\section{Conclusiones provisionales}

He descrito y analizado los aportes pedagógico-estéticos de Antenor Orrego en el contexto de la Bohemia de Trujillo/Grupo Norte: los motivos de límite y contradicción, la vida como estilo-metáfora personal, la búsqueda de la armonía vital. Se ha visto cómo la labor de Orrego no puede aislarse de su contexto nacional ni internacional: su lectura de Bergson a través del ojo crítico (híbrido, sui generis) de Pedro Zulen es un ejemplo de esto, pero también la hasta ahora no comentada lectura del biólogo Von Uexküll y la idea de la música como sistema de la naturaleza aplicado a la historia y a la estética.

Se ha comprobado cómo el amauta trujillano enmarca la obra de Spelucín y Vallejo en un contexto peruano y americano como posibilidades revolucionarias a través de la categoría de la virginización. Se ha comparado, con base en la clave interpretativa orreguiana, el poema "El Cristo de la sonrisa" de Spelucín y "Los Heraldos Negros" de Vallejo con el fin de comprenderlos no como opuestos sino como complementarios y, a su vez, se ha podido atisbar la vena de esperanza en la poesía de Vallejo.

Se ha buscado ofrecer un panorama complejo de las relaciones entre los miembros de la Bohemia de Trujillo que permita comprender a Vallejo no 
como un producto "extraordinario" de un país periférico a las vanguardias europeas sino como la consecuencia posible, el fruto, de una convivencia intelectual, emocional y estética de un grupo de jóvenes amigos cuyas relaciones generaron un originalísimo grupo de amautas-maestros. Se ha demostrado cómo la vanguardia se intersecta, se entrecruza (intercourse) con la pedagogía como necesarias labores de renovación social y cultural a todo nivel; este acercamiento busca promover un estudio de lo que se ha llamado pedagogos de vanguardia, uno de cuyos casos ejemplares es el de Antenor Orrego.

Finalmente, este trabajo es el inicio de una serie de artículos dedicados a conversar con los amautas, es decir, a hacer una búsqueda de aquellas figuras pedagógicas que hicieron posible la aparición o el fortalecimiento de las vanguardias, en plural, en el Perú (piénsese en el caso de José Antonio Encinas y Gamaliel Churata; motivo de un segundo artículo).

\section{Obras citadas}

Alva Castro, Luis et al. Antenor Orrego. La unidad continental y los orígenes de la modernidad en el Perú. Lima: Fondo Editorial del Congreso del Perú, 2008. Impreso.

Amauta (Lima, 1926-1930). Impreso.

Carapezza, Marco. "Armonia e contrappunto. Jacob von Uexküll tra etología e ontología". Animal Studies-Rivista Italiana di antispecismo, like me?, mente e diritti negli altri animali 2 (2013): 27-37. Impreso.

Crane, Hart. Complete Poems \& Selected Letters. New York:

The Library of America, 2006. Impreso.

Daly, Tara. "The vitalist aesthetics of Antenor Orrego and Cesar Vallejo". Chasqui 43.1 (mayo de 2014): 26. Impreso.

González Vigil, Ricardo. "La poesía peruana en los años 20". Revista de la Universidad Católica 5 (15 de agosto de 1979): 109-119. Impreso.

Heredia, Juan Manuel. "Deleuze, von Uexküll y 'la Naturaleza como música"” A Parte Rei-Revista de Filosofía (mayo de 2011): 1-8. Impreso.

Higgins, James. "La posición religiosa de César Vallejo a través de su poesía". Cahiers du monde hispanique et lusobrésilien 9 (1967): 47-58. Impreso.

Iberico, Mariano. El nuevo absoluto. Lima: Editorial Minerva, 1926. Impreso.

Jacoby, Roberto. El deseo nace del derrumbe. Acciones, conceptos, escritos. Ed. Ana Longoni. Barcelona: Ediciones La Central, 2011. Impreso.

Larroyo, Francisco. Historia general de la pedagogía: expuesta conforme al método de los tipos históricos de la educación (décima edición). México: Editorial Porrúa, 1994. Impreso. 
Leibner, Gerardo. "Pedro Zulen: del indigenismo paternalista al humanismo radical". Revista Europea de Estudios Latinoamericanos y del Caribe 63 (diciembre de 1997): 29-47. Impreso.

Mariátegui, José Carlos. Obras Completas. Tomo 4. Lima: Empresa Editora Amauta, S.A., 1959. Impreso.

Martínez, Juan Manuel. "Dios en la poesía de César Vallejo". Anales de Literatura Hispanoamericana 26.1 (1997): 195-206. Impreso.

Moreano, Cecilia. La literatura heredada: configuración del canon peruano de la segunda mitad del siglo XIX. Lima: Pontificia Universidad Católica del Perú - Instituto Riva-Agüero, 2004. Impreso.

Mosquera, Alberto. "Bohemia y Bohemios". Revista de la Facultad de Ciencias Económicas de la Universidad Nacional Mayor de San Marcos 10.25 (2005): 247-248.

Orozco, Richard Antonio. "La moral romántica en Mariano Ibérico y William James". Areté-Revista de Filosofía XXV-2 (2013): 283-305. Impreso.

Orrego, Antenor. "Comentario de César Vallejo (al Monólogo Eterno)". Notas Marginales (Colección Antenor Orrego $\mathrm{N}^{\circ}$ 1). Trujillo: Universidad Privada Antenor Orrego, 2007. 143. Impreso.

Orrego, Antenor. "El monólogo eterno" (1929). Obras Completas. Tomo I. Ed.

Luis Alva Castro. Lima: Casa Editorial Pachacútec, 2011. 81-116. Impreso.

Orrego, Antenor. "El trópico y el mar como ambientes poéticos".

Repertorio Americano-Semanario de Cultura Hispánica

XIII.6 (14 de agosto de 1926): 88-89. Impreso.

Orrego, Antenor. "Estación primera (artículos publicados en la revista Amauta)". Obras Completas. Tomo I. Ed. Luis Alva Castro.

Lima: Casa Editorial Pachacútec, 2011. 279-356. Impreso.

Orrego, Antenor. "La egolatría alemana" (1915). Antenor Orrego y la Bohemia de Trujillo. Lima: Fondo Editorial del Congreso del Perú, 2011. 290-293. Impreso.

Orrego, Antenor. Mi encuentro con César Vallejo. Bogotá: Tercer

Mundo Editores - Procultura, 1989. Impeso.

Orrego, Antenor. "Notas marginales, aforísticas" (1922). Obras Completas. Tomo I.

Ed. Luis Alva Castro. Lima: Casa Editorial Pachacútec, 2011. 23-80. Impreso.

Orrego, Antenor. "Palabras Prologales". La Nave Dorada.

Trujillo: Editorial "El Norte", 1926. Impreso.

Orrego, Antenor. "Palabras Prologales". Trilce. Lima: Talleres

Tipográficos de la Penitenciaría, 1922. Impreso.

Orrego, Antenor. "Pueblo-continente". Obras completas. Tomo I. Ed. Luis

Alva Castro. Lima: Editorial Pachacútec, 2011. 117-28o. Impreso. 
Parra, Clara María. "Ateneo de la Juventud y Revista Amauta: dos agentes colectivos de consolidación intelectual hispanoamericana". Anales de Literatura Hispanoamericana 42 (2013): 297-314.

Peirce, Charles S. "Evolutionary Love". The Monist 3 (1893): 176-200.

Peralta Rivera, Germán. Antenor Orrego y la Bohemia de Trujillo. Lima: Fondo Editorial del Congreso del Perú y Universidad Privada Antenor Orrego, 2011. Impreso.

Quintanilla, Pablo et al. Pensamiento y acción. La filosofía peruana a comienzos del siglo XX. Lima: Pontificia Universidad Católica del Perú, 2009. Impreso.

Robles, Elmer. "Pensamiento Educativo de Antenor Orrego". Revista Historia de la Educación Latinoamericana 13 (2009): 101-127. Impreso.

Seigel, Jerrold. Paris Bohème. Paris: Gallimard, 1991. Impreso.

Spelucín, Alcides. La Nave Dorada. Trujillo: Editorial "El Norte", 1926. Impreso.

Spelucín, Alcides. "Página Lírica". Repertorio Americano-Semanario de Cultura Hispánica XIII.6 (14 de agosto de 1926): 90-91. Impreso.

Tauro, Alberto. Amauta y su influencia (Biblioteca Amauta, Tomo 19). Lima: Empresa Editora Amauta, 1960. Impreso.

Vallejo, César. "La intelectualidad de Trujillo" (1918). Crónicas de Poeta. Prólogo y notas Manual Ruano. Caracas: Biblioteca Ayacucho Colección "La Expresión Americana", 1996. 201-206. Impreso.

Vallejo, César. Obras completas (primera edición). Lima: Banco de Crédito del Perú (Biblioteca Clásicos del Perú, 6), 1997. Impreso.

Uexküll, Johan Jakob von. Cartas biológicas a una dama [1920]. Santiago de Chile: Zig-zag, 19xx (no consigna fecha ni traducción). Impreso.

Uexküll, Johan Jakob von. Ideas para una concepción biológica del mundo (segunda edición). Trad. cast. R. M. Tenreiro. Buenos Aires: Espasa - Calpe, 1951. Impreso.

Uexküll, Johan Jakob von. Milieu animal et milieu humain [1934]. Trad. Charles Martin-Freville. Paris: Bibliothèque Rivages, 2010. Impreso.

Zulen, Pedro. La filosofía de lo inexpresable: bosquejo de una interpretación y una crítica de la filosofía de Bergson. Lima:

Talleres tipográficos de Sanmarti y Cia., 1920. Impreso. 